\title{
Dengue hemorrhagic fever as a rare cause of chronic immune thrombocytopenic purpura-a pediatric case report
}

\author{
V. Thadchanamoorthy ${ }^{1}$ and Kavinda Dayasiri ${ }^{*}$
}

\begin{abstract}
Background: Dengue is a common mosquito-borne infection in tropical countries. Dengue incidence in Sri Lanka is generally showing a rising trend. Both chronic immune thrombocytopenia purpura (ITP) children and chronic ITP triggered by dengue fever in the pediatric age group are rarely reported. This unusual presentation is a diagnostic challenge to clinicians. The authors have reported a pediatric patient who presented with chronic ITP following recovery from dengue hemorrhagic fever.

Case presentation: A 14-year-old previously healthy boy was initially managed as for dengue hemorrhagic fever. Following initial detection of persistent thrombocytopenia at 2 weeks post-discharge, his parents defaulted followup for 1 year as he remained asymptomatic. However, 1 year after initial admission, the child re-presented with ecchymotic patches and a platelet count of $30 \times 10^{3} /$ cumm. Review of serial blood counts performed during previous hospital admission and by his parents themselves revealed persistent thrombocytopenia over preceding 12 months. Subsequently, the child had an in-depth evaluation. The diagnosis of ITP was confirmed by ruling out differential diagnosis and he was managed as for chronic ITP. His platelet counts showed good response to oral corticosteroids and he is currently being followed up at the pediatric hematology clinic.

Conclusion: While reporting, a 14-year-old boy who developed chronic ITP following dengue hemorrhagic fever, this report highlights importance of frequent monitoring of blood counts to accurately detect and manage critical phase of dengue fever. The report also highlights the value of monitoring platelet counts in post-recovery phase to ensure they have normalized.
\end{abstract}

Keywords: Dengue, Immune thrombocytopenic purpura (ITP), Steroids

\section{Introduction}

Immune thrombocytopenic purpura (ITP) is a rare autoimmune disorder which can be either primary or secondary due to a number of medical disorders [1]. Secondary ITP is known to occur in association with systemic lupus erythematosus [2], anti-phospholipid antibody syndrome [3], immunodeficiency disorders [4], lymphoproliferative disorders [5], viral infections [6], and medications such as quinine and heparin [7]. Immune thrombocytopenia can be either acute or chronic. Acute ITP is more prevalent in

\footnotetext{
* Correspondence: kavindadayasiri@gmail.com

${ }^{2}$ Base Hospital Mahaoya, Mahaoya, Sri Lanka

Full list of author information is available at the end of the article
}

children following viral infections and $70-80 \%$ of these children recover without treatment [8]. However, a minority of children have persistently low platelets that lead to chronic ITP [9].

Dengue has a wide spectrum of clinical manifestations which range from mild to severe. Dengue fever has been rarely reported as a cause of acute ITP [10]. Similarly, dengue fever has rarely been reported to cause persistent thrombocytopenia [11]. In this report, the authors have described a pediatric patient who following recovery of dengue hemorrhagic fever, developed persistent thrombocytopenia leading to chronic ITP and subsequently, responded well to corticosteroids. The perpetuation of the low platelet count

(c) The Author(s). 2020 Open Access This article is licensed under a Creative Commons Attribution 4.0 International License, which permits use, sharing, adaptation, distribution and reproduction in any medium or format, as long as you give

appropriate credit to the original author(s) and the source, provide a link to the Creative Commons licence, and indicate if changes were made. The images or other third party material in this article are included in the article's Creative Commons licence, unless indicated otherwise in a credit line to the material. If material is not included in the article's Creative Commons licence and your intended use is not permitted by statutory regulation or exceeds the permitted use, you will need to obtain permission directly from the copyright holder. To view a copy of this licence, visit http://creativecommons.org/licenses/by/4.0/. 
probably occurred through immunological mechanisms, thus characterizing a condition of post-dengue ITP [12].This report highlights the importance of following-up platelet counts until normalization in children who have recovered from dengue.

\section{Case presentation}

A 14-year-old previously healthy boy presented with fever, headache, generalized body aches, and retroorbital pain for 5 days duration. As he had symptoms of dengue, he underwent dengue NS1 antigen testing and blood counts on day 3 of fever. Complete blood count (CBC) revealed a platelet count of $170 \times 10^{3} / \mathrm{cumm}$ and white cell count of $5.7 \times 10^{3} /$ cumm. Following NS1 antigen was detected positive, he had serial blood counts and supportive care during initial stage as guided by the general practitioner (GP). Patient was advised to have oral fluids approximately $75-100 \mathrm{ml}$ per hour. On day 5 of fever, platelet count dropped to $98 \times 10^{3} / \mathrm{cumm}$ and white cell count dropped to $4.2 \times 10^{3} / \mathrm{cumm}$, and he was admitted for in-patient observation and management. On admission to hospital, he had stable vital signs which included pulse rate of 140 beats per minute, blood pressure-100/70mmg, capillary refill time of less than $2 \mathrm{~s}$, and hematocrit rise of $16.7 \%$ from baseline (42\% on admission with baseline hematocrit being 36\%). During initial $24 \mathrm{~h}$ following admission, he developed vomiting and abdominal pain but had no bleeding manifestations.

Physical examination revealed generalized flushing, right hypochondrial tenderness, $3 \mathrm{~cm}$ hepatomegaly, and no signs of leakage. Point of care ultrasound revealed a mild pleural effusion and thickened gall bladder wall. Investigations revealed leucopenia $(2.2 \times 103 / \mathrm{cumm})$, thrombocytopenia (platelet count-68 $\times 10^{3} / \mathrm{cumm}$ ), and deranged liver functions (Alanine aminotransferase$88 \mathrm{U} / \mathrm{L}$, Aspartate transaminase-124 U/L). C-reactive protein and renal functions were normal. Subsequently, he was managed as for dengue hemorrhagic fever in high dependency care unit. Platelets further dropped to the lowest count of $6 \times 10^{3} /$ cumm on day 7 . However, there were no bleeding manifestations during the course of illness. Dengue serology including both IgM and IgG were positive on day 7 of illness. He recovered on day 11 of illness with evidence of rise of platelet counts. The cell indices at discharge on day 11 were white blood cells$7.5 \times 10^{3} /$ cumm and platelet counts-52 $\times 10^{3} /$ cumm. Follow-up was arranged with local GP to review platelet counts in 3 days and patient was also requested for a follow-up appointment at the tertiary care hospital in 2 weeks.

Platelet counts were followed up to ensure complete recovery although platelet count remained at $47 \times 10^{3} /$ cumm at 2-week post-discharge review at the tertiary care hospital. He was subsequently admitted as in- patient for further evaluation although no significant abnormality was found. Platelet count at one-month post-discharge was $100 \times 10^{3} / \mathrm{cumm}$. Unfortunately, his parents defaulted follow-up as investigations were normal apart from thrombocytopenia and the patient represented with multiple purpura for 1 week duration at 1-year post-discharge. The parents had managed by their own to repeat blood counts over period they defaulted clinic follow-up, and the records revealed persistent thrombocytopenia (ranged from 30 to $45 \times 10^{3} /$ cumm).

He was investigated in-depth at this point for persistent thrombocytopenia. Average absolute lymphocyte over the period of 1 year was $3.26 \times 10^{3} /$ cumm (based on five previous records during the period they defaulted treatment), and the latest lymphocyte count was $2.6 \times 10^{3} /$ cumm. Erythrocyte sedimentation rate was $15 \mathrm{~mm} / 1$ st hour. Antinuclear antibody, anti-double standard DNA, and antiphospholipid antibodies were negative. Mycoplasma, influenza cytomegalovirus, hepatitis $\mathrm{B}$, hepatitis $\mathrm{C}$, human immunodeficiency virus, and Epstein-Barr virus serology were also negative. Past medical history was not supportive of immunodeficiency and baseline immunodeficiency screen (serum immunoglobulins and complement levels) was negative. There was no recent history of MMR (mumps-measles-rubella) vaccination or use of platelet lowering medications prior to first detection of thrombocytopenia. Blood film showed normal morphology of cells including platelets and showed only thrombocytopenia. Bone marrow examination showed megakaryocytes but was otherwise completely normal. The clinical evaluation and investigations ruled out differential diagnosis confirming the diagnosis of chronic ITP secondary due to dengue infection. Since the child had persistent thrombocytopenia for over 12 months, he was managed as for chronic ITP. The child was commenced on corticosteroids and currently being followed-up at pediatric hematology clinic.

\section{Discussion}

Immune thrombocytopenic purpura is an autoimmune disorder characterized by low platelet count and skinmucosal bleeding [13].There are a variety of viruses implicated in the etiopathogenesis of ITP, especially in children, and include human immunodeficiency virus1 , hepatitis $C$, varicella-zoster, rubella, influenza, and Epstein-Barr virus [14]. The exact role of viruses in the pathogenesis of this disorder remains ambiguous although ITP typically shadows a viral illness in children. Thrombocytopenia associated with viral infection seems to result both from a reduction in the production of platelets from megakaryocytes and from a decrease in the half-life of platelets. The underlying mechanisms of post-viral immune thrombocytopenia include pathogenic platelet auto-antibodies [15], impaired 
megakaryocyte function [16], and T-cell mediated platelet destruction [17]. It is believed that viral antigens mimic platelets (molecular mimicry) triggering off formation of platelet auto-antibodies [18].

Pathogenesis of ITP is understood mainly based on adult studies, and evidence regarding pathophysiology of pediatric chronic ITP is scarce. Chronic ITP is diagnosed when thrombocytopenia persists beyond 12 months in patients with acute ITP [19]. Persistently elevated levels of platelet associated IgG are seen with chronic ITP and support the speculation of the mechanisms of persistent immune platelet destruction. Spleen has a crucial role in both antibody production and platelet destruction. Absolute lymphocyte counts at the initial diagnosis of ITP were predictive variables for the development of chronic ITP in children [20]. The risk for chronic ITP was correlated with lower initial lymphocyte counts [18]. In this patient, lymphocyte count remained within low normal range throughout the course. The initial thrombocytopenia in dengue is thought to be due to bone marrow suppression by the virus. Subsequent thrombocytopenia with rash is due to immune-mediated platelet destruction which is supported by demonstration of virus-antibody complexes on the platelet surface in patients with dengue hemorrhagic fever [21]. It has been shown that patients with dengue fever have IgM anti-platelet antibodies [22].

Dengue fever has been reported in patients with ITP [23]. However, the reverse is uncommon and unusual and often leads to diagnostic challenges. It is also theoretically possible that children with co-existing dengue hemorrhagic fever and immune thrombocytopenia are more likely to have bleeding-related complications due to more pronounced thrombocytopenia. Although platelet counts dropped to $6 \times 10^{3}$ /cumm in the reported child, no bleeding manifestations were observed and discharged with the platelet of $52 \times 10^{3} \mathrm{~mm} / \mathrm{l}$. The reported child had a rising platelet count $\left(100 \times 10^{3} /\right.$ cumm $)$ and was clinically well at 1 month review. Subsequently, the patient defaulted follow-up as he remained well and due to several social reasons even though the parents knew that their child had persistently low platelet counts. Parents repeated platelet counts frequently and presented to hospital in 1 year only after appearance of symptoms. Although this is not an absolutely correct practice in most other countries, most patients in Sri Lanka are able to get complete blood counts done by their own as dengue is endemic and patients often have free access to visit laboratories for basic blood investigations without needing medical consultations. Though this practice obviously reduces their cost of consultation, time they spend in government hospitals and also cross infection from other patients in overcrowding conditions, there is a high probability of delayed presentations to hospital and potentially bring unfavorable outcomes both to the patient and state.
There are only a few case reports of dengue fever which led to ITP and the majority of these reports were from adult patients. In reported cases, thrombocytopenia was treated with intravenous immunoglobulin [24], and oral or intravenous steroids [11, 25-29]. Boo et al. [11] and Kohli et al. [25] reported pediatric cases that did not respond well to the initial corticosteroid therapy and complicated with intracranial bleeding [11]. Kumar et al. reported an adult patient who showed satisfactory response to intravenous immunoglobulin following initial lack of improvement with intravenous methylprednisolone [24]. However, the cases reported by Bhalla et al. and Leong et al. had an uncomplicated course with good response to corticosteroids.

This case report highlights the importance of early admission to hospital as the reported patient presented during critical phase of dengue hemorrhagic fever despite early diagnosis. This child's diagnosis of dengue fever was confirmed on day 3 of the illness. The primary care doctor (GP) could have referred him for early inpatient care. However, he may have considered the cost, overcrowding at local hospitals, parents' wishes, and the fact that dengue patients with low white cell counts are susceptible to nosocomial infections [30]. He decided to give ambulatory care. Many dengue patients worldwide get ambulatory care [31]. However, if the treating doctor takes a calculated risk and go for ambulatory care, the patient has to be monitored and reviewed frequently (current National Guidelines of Sri Lanka for Management of Dengue in Children and Adolescents). For example, $\mathrm{CBC}$ has to be reviewed once a day if the platelet count is $>150,000$ per cu. $\mathrm{mm}$. Once the platelet count decreases below 150,000 per $\mathrm{cu}$. $\mathrm{mm}, \mathrm{CBC}$ has to be reviewed twice daily. However, this child's $\mathrm{CBC}$ was repeated on day 5 (not on day 4) and he was admitted while in critical phase of dengue hemorrhagic fever. Frequent review of $\mathrm{CBC}$ could have prevented this presentation and potential complications.

The report also strengthened the rationale of following up all patients with dengue fever until the platelet counts normalize. The clinicians should have a broader approach to persistent thrombocytopenia, and malignancies and connective tissue disorders should be ruled out as a priority. Steroids must be commenced only after ruling out hematological malignancies. The key objective in treating ITP is to maintain the platelet count at a level that would not cause major bleeding. It is widely accepted that it is not necessary to treat asymptomatic patients with moderate thrombocytopenia. Intravenous immune globulin ( $1 \mathrm{~g} / \mathrm{kg} /$ day for 2 to 3 consecutive days) is used for treating internal bleeding when the platelet count is less than $5000 / \mu \mathrm{l}$ despite corticosteroid therapy for many days, or when there is progressive or extensive purpura. When treatment is required for immune thrombocytopenic 
purpura, the treatment of choice is oral prednisolone which is given at 1 to $2 \mathrm{mg} / \mathrm{kg} /$ day [32].

\section{Conclusion}

While reporting a 14-year-old boy who developed chronic ITP following dengue hemorrhagic fever, this report highlights importance of frequent monitoring of blood counts to accurately detect and manage critical phase of dengue fever. The report also highlights the value of monitoring platelet counts in post-recovery phase to ensure they have normalized.

\section{Abbreviations}

CBC: Complete blood count; ITP: Immune thrombocytopenic purpura

\section{Acknowledgements}

None

\section{Authors' contributions}

$\mathrm{VT}$ led clinical management of the patient and wrote manuscript. KD performed literature survey and wrote and edited the manuscript. Both authors read and approved final version of the manuscript.

\section{Funding}

No funding was received.

\section{Availability of data and materials}

The data that support the findings of this case report are available from the Medical Records Department, Batticaloa Teaching Hospital, but restrictions apply to the availability of these data, which were used under license for the current report and so are not publicly available. Data are, however, available from the authors upon reasonable request and with permission of the Medical Records Department, Batticaloa Teaching Hospital, Sri Lanka.

\section{Ethics approval and consent to participate}

Not applicable

\section{Consent for publication}

Written informed consent was obtained from patient's legal guardian for publication of this case report. A copy of the written consent is available for review by the Editor-in-Chief of this journal.

\section{Competing interests}

The authors declare that there is no conflict of interests regarding the publication of this paper.

\section{Author details}

${ }^{1}$ Faculty of Health Care Sciences, Eastern University, Chenkalady, Sri Lanka.

${ }^{2}$ Base Hospital Mahaoya, Mahaoya, Sri Lanka.

Received: 27 May 2020 Accepted: 14 July 2020

Published online: 20 July 2020

\section{References}

1. Kistangari G, McCrae KR. Immune thrombocytopenia. Hematol Oncol Clin North Am. 2013;27(3):495-520. https://doi.org/10.1016/j.hoc.2013.03.001.

2. Arnal C, Piette JC, Leone J, Taillan B, Hachulla E, Roudot-Thoraval F, et al. Treatment of severe immune thrombocytopenia associated with systemic lupus erythematosus: 59 cases. J Rheumatol. 2002;29(1):75-83.

3. Lipp E, von Felten A, Sax H, Muller D, Berchtold P. Antibodies against platelet glycoproteins and antiphospholipid antibodies in autoimmune thrombocytopenia. Eur J Haematol. 1998;60:282-8.

4. Pituch-Noworolska A, Siedlar M, Kowalczyk D, Szaflarska A, Błaut-Szlósarczyk A, Zwonarz K. Thrombocytopenia in common variable immunodeficiency patients - clinical course, management, and effect of immunoglobulins. Cent Eur J Immunol. 2015;40(1):83-90. https://doi.org/10.5114/ceji.2015.50838.

5. Teachey DT. New advances in the diagnosis and treatment of autoimmune lymphoproliferative syndrome. Curr Opin Pediatr. 2012;24(1):1-8.
6. Liebman HA. Viral-associated immune thrombocytopenic purpura. Hematology Am Soc Hematol Educ Program. 2008:212-8.

7. Aster RH, Curtis BR, McFarland JG, Bougie DW. Drug-induced immune thrombocytopenia: pathogenesis, diagnosis, and management. J Thromb Haemost. 2009;7(6):911-8. https://doi.org/10.1111/j.1538-7836.2009.03360.x.

8. Recht M. Thrombocytopenia and anemia in infants and children. Emerg Med Clin North Am. 2009;27:505-23. https://doi.org/10.1016/j. emc.2009.04.009.

9. Del Vecchio GC, De Santis A, Accettura L, De Mattia D, Giordano P. Chronic immune thrombocytopenia in childhood. Blood Coagul Fibrinol. 2014;25: 297-9. https://doi.org/10.1097/MBC.0000000000000043.

10. Ramírez-Fonseca T, Segarra-Torres A, Jaume-Anselmi F, Ramírez-Rivera J. Dengue fever: a rare cause of immune thrombocytopenia. Bol Asoc Med PR. 2015;107(2):51-3.

11. Boo YL, Lim SY, P'ng HS, Liam C, Huan NC, et al. Malays Fam Physician. 2019;14(3):71-3 Published 2019 Dec 31.

12. Cines DB, Blanchette VS. Immune thrombocytopenic purpura. N Engl J Med. 2002;346(13):995-1008

13. Zainal A, Salama A, Alweis R, et al. J Community Hosp Intern Med Perspect. 2019;9(1):59-61Published 2019 Feb 11. https://doi.org/10.1080/20009666. 2019.1565884.

14. Rand ML, Wright JF. Virus-associated idiopathic thrombocytopenic purpura. Transfus Sci. 1998;19(3):253-9. https://doi.org/10.1016/s09553886(98)00039-3.

15. Nielsen $\mathrm{OH}$, Tuckuviene R, Nielsen KR, Rosthoj S. Flow cytometric measurement of platelet-associated immunoglobulin in children with newly diagnosed immune thrombocytopenia. Eur J Haematol. 2016;96:397-403. https://doi.org/10.1111/ejh.12605.

16. McMillan R, Wang L, Tomer A, Nichol J, Pistillo J. Suppression of in vitro megakaryocyte production by antiplatelet autoantibodies from adult patients with chronic ITP. Blood. 2004;103:1364-9. https://doi.org/10.1182/ blood-2003-08-2672

17. Qiu J, Liu X, Li X, Zhang X, Han P, Zhou H, et al. CD8(+) T cells induce platelet clearance in the liver via platelet desialylation in immune thrombocytopenia. Sci Rep. 2016;6:27445. https://doi.org/10.1038/srep27445.

18. Zhang W, Nardi MA, Borkowsky W, Li Z, Karpatkin S. Role of molecular mimicry of hepatitis C virus protein with platelet GPIIla in hepatitis C-related immunologic thrombocytopenia. Blood. 2009;113:4086-93. https://doi.org/ 10.1182/blood-2008-09-181073.

19. Palau J, Jarque I, Sanz MA. Long-term management of chronic immune thrombocytopenic purpura in adults. Int J Gen Med. 2010;3:30511 Published 2010 Oct 5. https://doi.org/10.2147/JJGM.S4722.

20. Akbayram S, Karaman K, Dogan M, et al. Initial lymphocyte count as prognostic indicator for childhood immune thrombocytopenia. Indian J Hematol Blood Transfus. 2017;33:93-6 https://doi.org/10.1007/s12288016-0664-0

21. Sellahewa KH. Haematological disturbances in dengue Haemorrhagic fever its pathogenesis and management perspectives. Hematol Oncol Res. 2015 1(3):15-24.

22. Lin CF, Lei HY, Liu CC, Liu HS, Yeh TM, Wang ST, et al. Generation of IgM antiplatelet autoantibody in denque patients. J Med Virol. 2001;63(2):143-9.

23. Ehelepola ND, Gunawardhana MB, Sudusinghe TN, Sooriyaarachchi SK, Manchanayake SP, Kalupahana KL. A dengue infection without bleeding manifestations in an adult with immune thrombocytopenic purpura. Trop Med Health. 2016:44-36Published 2016 Nov 7. https://doi.org/10.1186/ s41182-016-0036-3.

24. Kumar P, Charaniya R, Ghosh A, Sahoo R. Intravenous immunoglobulin responsive persistent thrombocytopenia after dengue Haemorrhagic fever. J Clin Diagn Res. 2016;10(4):OD10-1. https://doi.org/10.7860/JCDR/ 2016/17770.7605

25. Kohli U, Saharan S, Lodha R, Kabra SK. Persistent thrombocytopenia following dengue shock syndrome. Indian J Pediatr. 2008;75(1):82-3.

26. Bhalla A, Bagga R, Dhaliwal LK, Sharma R, Varma S. Steroid responsive prolonged thrombocytopenia in dengue. Indian J Med Sci. 2010;64:90-3.

27. Prashanth GP, Mugali SB. Persistent thrombocytopenia in dengue hemorrhagic fever. Indian Pediatr. 2011:48(9):737.

28. Leong KW, Srinivas P. Corticosteroid-responsive prolonged thrombocytopenia following dengue hemorrhagic fever. Med J Malaysia. 1993;48(3):369-72

29. Dinesh N, Patil VD. Persistent thrombocytopenia after dengue hemorrhagic fever. Indian Pediatr. 2006;43(11):1010-1. 
30. Ehelepola NDB, Rajapaksha RKGM, Dhanapala DMUB, Thennekoon TDK, Ponnamperuma S. Concurrent methicillin-resistant Staphylococcus aureus septicemia and pyomyositis in a patient with dengue hemorrhagic fever: a case report. BMC Infect Dis. 2018;18(1):99Published 2018 Feb 27. https://doi. org/10.1186/s12879-018-3012-1.

31. Shepard DS, Undurraga EA, Halasa YA, Stanaway JD. The global economic burden of dengue: a systematic analysis. Lancet Infect Dis. 2016;16(8):935-41. https://doi.org/10.1016/S1473-3099(16)00146-8.

32. George JN, Woolf SH, Raskob GE, Wasser JS, Aledort LM, Ballem PJ, et al. Idiopathic thrombocytopenic purpura: a practice guideline developed by explicit methods for the American Society of Hematology. Blood. 1996;88(1):3-40.

\section{Publisher's Note}

Springer Nature remains neutral with regard to jurisdictional claims in published maps and institutional affiliations.

Ready to submit your research? Choose BMC and benefit from:

- fast, convenient online submission

- thorough peer review by experienced researchers in your field

- rapid publication on acceptance

- support for research data, including large and complex data types

- gold Open Access which fosters wider collaboration and increased citations

- maximum visibility for your research: over $100 \mathrm{M}$ website views per year

At BMC, research is always in progress.

Learn more biomedcentral.com/submissions 